Annals of the University of Craiova

The Chemistry Series

Volume XLVII, No. 2 (2021) 60-74

homepage:chimie.ucv.ro/anale

\title{
Comparative study on the effects of wheat plants exposure to gibberellic acid and salicylic acid
}

\section{Research article}

\section{Georgeta Ciobanu ${ }^{* 1}$, Cătălina Ionescu ${ }^{1}$}

${ }^{1}$ University of Craiova, Faculty of Sciences, Department of Chemistry, Calea Bucuresti, 107i, Craiova, Romania

*E-mail: geo_ciobanu20@yahoo.com

Received: 01.10.2021 / Accepted: 05.11.2021 / Published: 27.12.2021

\begin{abstract}
We set out to characterize some aspects of growth and metabolism of wheat seedlings that have grown for 7 days on media supplemented with gibberellic acid (GA3) or salicylic acid (SA), at concentrations of $10 \mu \mathrm{mol} \cdot \mathrm{L}^{-1}$ and $100 \mu \mathrm{mol} \cdot \mathrm{L}^{-1}$. Compared to control plants, increased concentration of glucose and lipid peroxidation products were observed in GA3 series, while higher levels of soluble proteins, glucose, acid phosphatase and peroxidase activity were measured in SA series. Data from photosynthetic pigment analysis pointed out minor differences regarding chlorophylls and carotenoids content in plants' leaves, both within and between the groups. Although total carotenoid content didn't vary markedly among the experimental variants, certain changes of the relative contribution of the pigments in the carotenoid pool were observed, mainly a decrease of neoxanthin content paralleled by an increase of violaxanthin content. However, as the biometric data have shown, plant growth was neither inhibited nor stimulated, irrespective of the growth conditions. The observed modulation of certain biochemical parameters may be considered as part of the plants' adaptive responses to an environmental challenge, where the differences between GA3 and SA regarding bioavailability, mobility and specific mechanisms of action underlie the different outcomes.
\end{abstract}

DOI: 10.52846/AUCCHEM.2021.2.07 
Keywords: gibberellic acid, salicylic acid, wheat plants, antioxidant response, photosynthetic pigments.

\section{INTRODUCTION}

Phytohormones are endogenous substances that, at low concentrations, influence all the aspects of plants' life. Structural diversity of these regulatory molecules ranges from the simple, gaseous ethylene to phenolic acids (i.e. salicylic acid), amino acids derivatives or more complex polycyclic structures, like the tetracyclic diterpenes collectively named gibberellins, and the polyhydroxylated steroids named brassinosteroids. Certain phytohormones are structurally resembling to animal hormones; although their physiological roles are different, their action may be similar at the molecular level.

Phytohormones were initially qualified and classified according to their main observed function, as follows: growth hormone (gibberellins), stress hormone (abscisic acid), ripening hormone (ethylene), and so on. Later, it became obvious that this simplifying classification can't include all the effects that each of the plant hormones exerts. Intricate signalling networks and hormone crosstalk enable these substances with important roles in plant development and response to various abiotic and biotic stresses to be active [1-4]. Unravelling their mechanisms of action at molecular level is still in progress, as are the studies on phytohormones engineering in model plants or crop plants [5-8].

Phytohormones are chemical regulators that cross the interspecies barriers. It is known that certain of the plant hormones exhibit anti-inflammatory and pro-metabolic effects in humans. In this regard, salicylic acid has already made history, but also the more recent characterized strigolactones have the potential to prevent and treat inflammation [9]. Some of the molecules that exert hormonal roles in plants are also produced by human cells and gut microbiome, influencing metabolism and immune response. Thus, certain phytohormones are considered as promising nutraceuticals against metabolic syndrome and comorbid diseases [10]. 
Exogenous applied plant hormones, hormone analogues, agonists or antagonists, are used (as appropriated) for germination and growth stimulation, ripening promotion or delay, and stress alleviation. We aimed to assess the effect of exogenous supply of either gibberellic acid or salicylic acid to wheat plantlets that have been grown for short duration in laboratory conditions, on solidified nutrient solutions.

\section{MATERIALS AND METHODS}

\subsection{Materials}

To obtain the stock solutions of gibberellic acid, the commercial preparation GibbA3 was used, conditioned as $5 \mathrm{~g}$ soluble tablets containing 20\% GA GA $_{3}$ GA 3 per tablet) and effervescent co-excipients. The other solutions used in the experiments were prepared with analytical grade reagents. Wheat caryopses (Triticum aestivum L, cv. PB1) were obtained from the Agricultural Research and Development Station Simnic, Dolj.

\subsection{Plant growth assay}

24 Hours after the onset of imbibition, wheat caryopses germinated between two layers of moistened filter paper were planted on agar solidified growth media containing either gibberellic acid or salicylic acid, in Petri dishes (20 caryopses per $50 \mathrm{~mL}$ medium). Each of the two hormones was tested at two different concentrations: $10 \mu \mathrm{mol} \cdot \mathrm{L}^{-}$ ${ }^{1}$ and $100 \mu \mathrm{mol} \cdot \mathrm{L}^{-1}$, with plants cultivated on hormone-free media as control. The Petri dishes were kept for 7 days in laboratory conditions under natural lighting and temperature of $25 / 20^{\circ} \mathrm{C}$.

Seven days-old wheat seedlings were harvested and the length of theirs stems and roots were registered. Mean values and standard deviations of plant length were calculated as previously described [11]. The fresh weight (FW) and dry weight (DW) of the plants was measured with an analytical scale Precisa XB 120A. 


\subsection{Biochemical assays}

From each of the experimental variants, root samples weighing about $0.2 \mathrm{~g}$ were collected and ground with quartz sand and $0.1 \mathrm{~mol} \cdot \mathrm{L}^{-1}$ Tris- $\mathrm{HCl}$ buffer, $\mathrm{pH} 7.2$ (3 mL per sample), using a mortar and pestle. The obtained tissue homogenates were centrifuged at 10,000 rpm, in a Sigma $2-16 \mathrm{~K}$ refrigerated centrifuge, for 10 minutes at $4^{\circ} \mathrm{C}$. The collected supernatants were used for biochemical assays. Total peroxidase activity (EC 1.11.1.7) was measured using guaiacol as reducing substrate [12], acid phosphatase activity (EC 3.1.3.2) was assayed with pnitrophenol as substrate [13] and the Bradford method was used for total soluble protein evaluation [14]. In the extracts, low molecular mass metabolites were also assayed: the secondary lipid peroxidation products, using TBA method [15], and glucose content by the coupled enzymatic reaction of glucose oxidase and peroxidase. Data presented are averages of three measurements \pm standard deviations.

Photosynthetic pigments in wheat leaves were also extracted and analysed: samples of about $0.03 \mathrm{~g}$ of fresh apical leaf tissue were ground and extracted in $3 \mathrm{~mL}$ pure acetone. The obtained extracts were centrifuged for $10 \mathrm{~min}$ at $10000 \mathrm{rpm}$; the supernatants were decanted in glass cuvette with $10 \mathrm{~mm}$ optical path length, and the absorption spectrum of each of them was recorded in the visible range. Quantification of the photosynthetic pigments in the leaf extracts was done by fitting the absorption spectra (from 350 to $750 \mathrm{~nm}$ ) with the appropriated GPS equations [16].

A Varian Cary $50 \mathrm{UV}-\mathrm{V}$ is spectrophotometer was used for the spectrophotometric measurements. All the biochemical parameters were expressed in appropriated units, and reported to the dry weight (DW) of the analysed samples.

\section{RESULTS AND DISCUSSION}

\subsection{Antioxidant and metabolic indexes of wheat plants}

Secondary lipid peroxidation products. Lipid hydroperoxides, the primary products of lipids oxidation, are very reactive and unstable. 
Thus, the more stable secondary products are often the analytes of choice for assessing advanced oxidation, with malondialdehyde (MDA) as reference compound [17].

In the roots of wheat plants unexposed to exogenous phytohormones (control), the concentration of secondary lipid peroxidation products (TBARS-thiobarbituric reactive substances), expressed as malondialdehyde equivalents, was $0.855 \pm 0.05 \mu \mathrm{mol} \cdot \mathrm{g}^{-1}$ DW. The plants grown on media supplemented with $\mathrm{GA}_{3}$ had greater concentration of TBARS in theirs roots, with $70 \%$ and $40 \%$, respectively, compared to control (Figure 1). At $10 \mu \mathrm{mol} \cdot \mathrm{L}^{-1} \mathrm{SA}$, TBARS concentration didn't vary significantly relative to the control value, but it increased by $20 \%$ in the plants exposed to $100 \mu \mathrm{mol} \cdot \mathrm{L}^{-1}$ of exogenous SA.

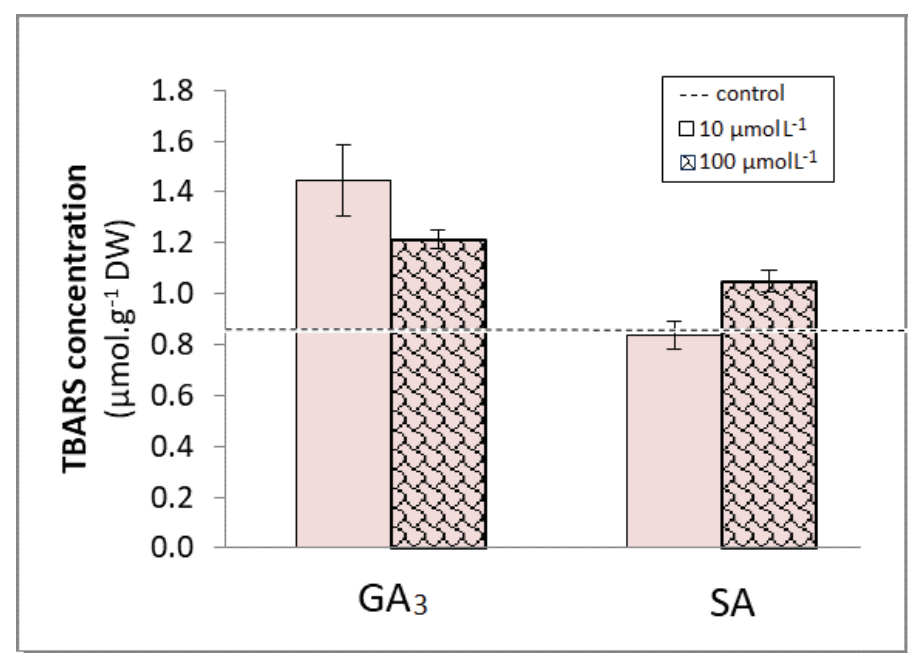

Figure 1. TBARS concentration in the roots of wheat plants exposed to GA3 or SA (vertical bars) compared to control (dotted line)

Advanced lipid peroxidation may result from excess generation of reactive oxygen species; however, it is associated not only with cell damage, but also with cell signalling and adaptive responses [18]. According to recent studies, MDA can exert a positive role by activating regulatory genes involved in plant defence and development [19]. Thus, MDA concentrations are indicators of acclimatization processes rather than deterioration, under conditions of efficient redox signalling. In this case, even if the exposure to exogenous hormones was stressful, 
signalling by lipid peroxidation may have helped the plants cope with the stress, because their growth parameters did not register a significant decrease compared to the control.

Soluble peroxidase activity. In the absence of exogenous GA3 or SA, peroxidase activity in the roots of wheat plants was of $740.38 \pm 39.82 \mathrm{U}$. $\mathrm{g}^{-1}$ DW. Compared to control, low effect or no effect on peroxidase activity was observed at the two tested concentrations of GA3 (Figure 2). Contrasting results were observed in the plants exposed to exogenous SA, where the activity of non-specific peroxidases increased by $40 \%$ relative to control, regardless of the concentration of the hormone.

In both experimental series, the TBARS concentration appears to vary in the opposite direction to the peroxidase activity. Increased TBARS activity in the roots of $\mathrm{GA}_{3}$ exposed plants were accompanied by peroxidase activities close to control level. In SA series, the increased peroxidase activity, irrespective of the hormone concentration, was accompanied by no or low variation of TBARS compared to control.

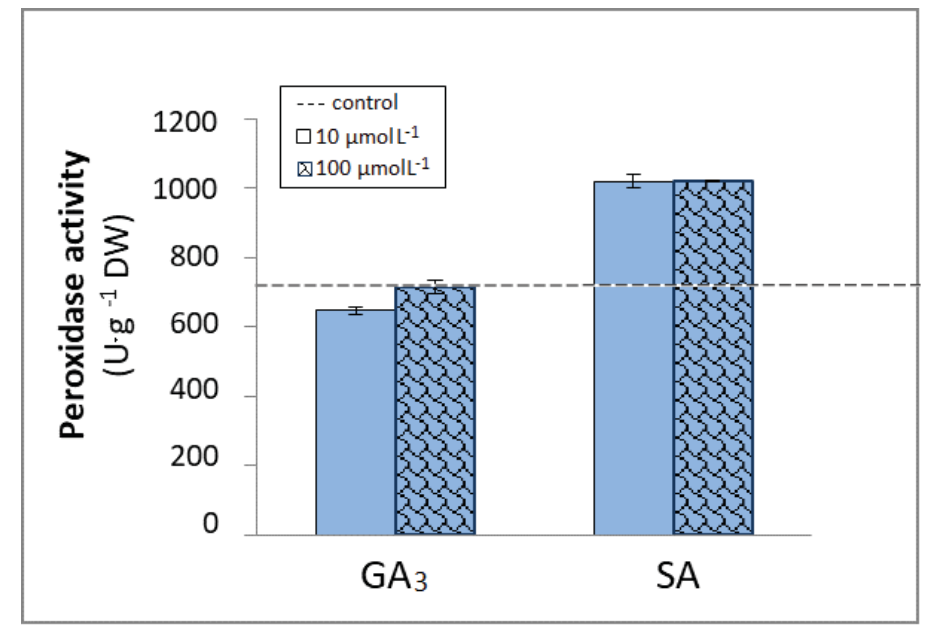

Figure 2. Peroxidase activity in the roots of wheat plants exposed to GA3 or SA (vertical bars), compared to control (dotted line)

Acid phosphatase activity. In wheat plants grown on hormone free media (control), acid phosphatase activity in the roots was $3.6 \pm 0.41 \mathrm{U} \cdot \mathrm{g}^{-1}$ DW. Acid phosphatase activity in the roots of GA3 exposed plants did not vary significantly from control, regardless the concentration of the added gibberellin. In plants grown on media supplemented with 
salicylic acid, phosphatase activity increased relative to control by about $50 \%$ at the two tested concentrations; the marked increase and the lack of dose-response correlation is suggestive for the existence of a threshold beyond which the response appears (Figure 3).

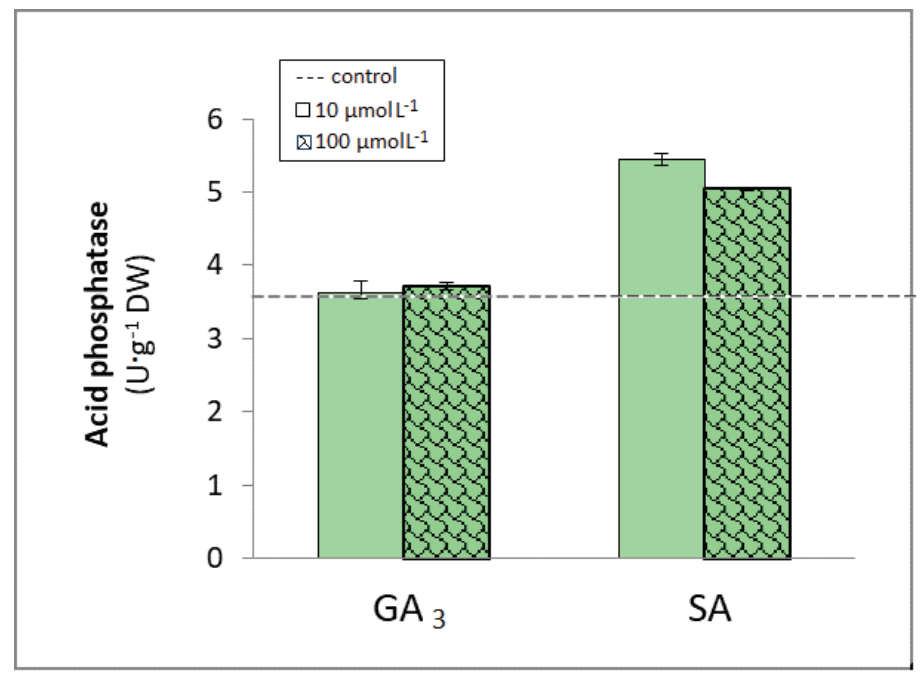

Figure 3. Acid phosphatase activity in the roots of wheat plants exposed to $\mathrm{GA}_{3}$ or SA (vertical bars), compared to control (dotted line)

Glucose and soluble protein content. The concentration of glucose in the roots of wheat plants unexposed to exogenous $\mathrm{GA}_{3}$ or SA was $13.42 \pm 1.09 \mathrm{mg} \cdot \mathrm{g}^{-1} \mathrm{DW}$. At $10 \mu \mathrm{mol} \cdot \mathrm{L}^{-1} \mathrm{GA}_{3}$, glucose concentration has increased with $40 \%$ compared to control; no significant difference from control value was observed in the plants exposed to 10 times greater GA3 concentration (Figure 4). A marked, dose dependent increase of glucose concentration, with $50 \%$ and $130 \%$ respectively compared to control plants, was observed consecutive to SA exposure.

Glucose is not only a carbon source but also an important signalling molecule that improves photosynthetic efficiency, plant-water relation and growth [20].

In the absence of $\mathrm{GA}_{3}$, soluble proteins concentration in the roots of wheat plants was $50.27 \pm 4.92 \mathrm{mg} \cdot \mathrm{g}^{-1} \mathrm{DW}$. Compared to control, no significant differences were observed in the plants exposed to hormones, except for the treatment with $100 \mu \mathrm{mol} \cdot \mathrm{L}^{-1} \mathrm{SA}$ which led to a $26 \%$ increase in root protein content (Figure 5). 


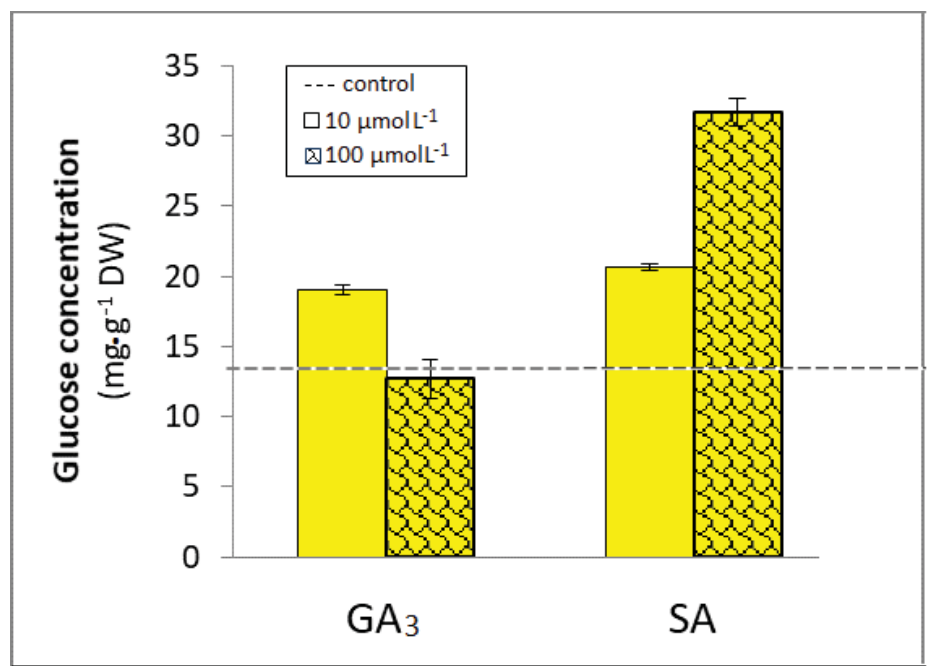

Figure 4. Glucose concentration in the roots of wheat plants exposed to $\mathrm{GA}_{3}$ or SA (vertical bars), compared to control (dotted line)

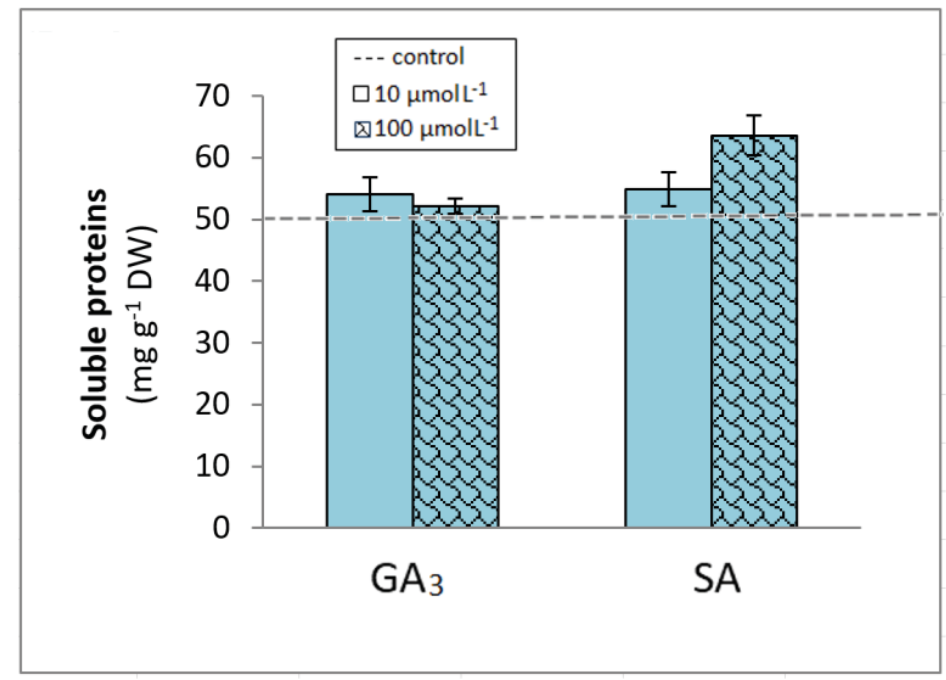

Figure 5. Soluble protein concentration in the roots of wheat plants exposed to $\mathrm{GA}_{3}$ or SA (vertical bars), compared to control (dotted line)

\subsection{Photosynthetic pigments in wheat plants' leaves}

Chlorophyll a (Chl a) concentration in wheat plants grown on media without exogenous supply of phytohormones (control) was $10.04 \pm 0.74 \mu \mathrm{mol} \cdot \mathrm{g}^{-1} \mathrm{DW}$. Chl a content increased with $10 \%$ compared to control in wheat plant exposed to $10 \mu \mathrm{mol} \cdot \mathrm{L}^{-1} \mathrm{GA}$, while a $25 \%$ increase 
was observed in the plants grown on media with $10 \mu \mathrm{mol} \cdot \mathrm{L}^{-1} \mathrm{SA}$. Greater concentrations of $\mathrm{GA}_{3}$ or SA restored the $\mathrm{Chl}$ a quantity to the level observed in control plants (Figure 6).

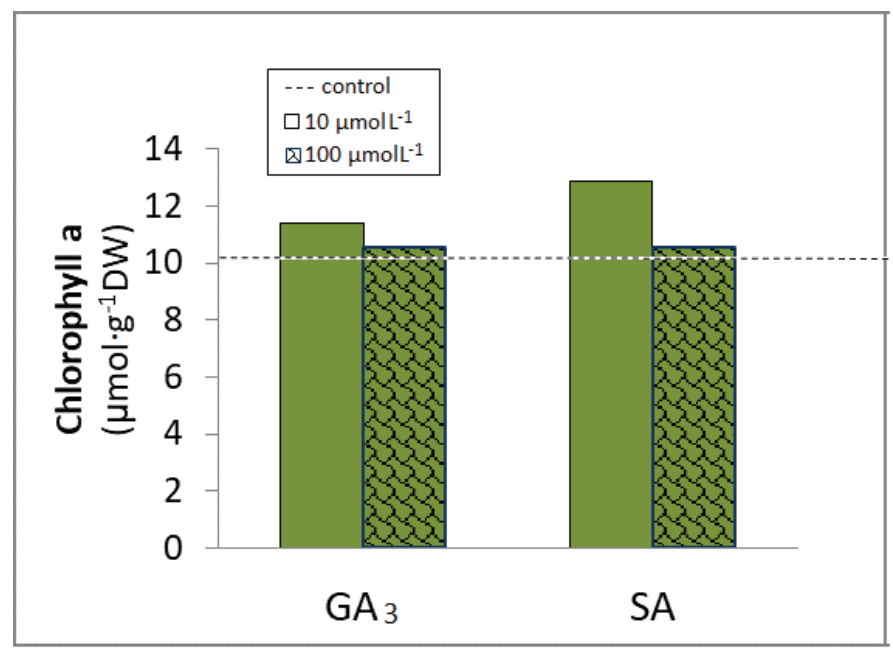

Figure 6. Chlorophyll a concentration in the leaves of wheat plants exposed to $\mathrm{GA}_{3}$ or SA (vertical bars), compared to control (dotted line)

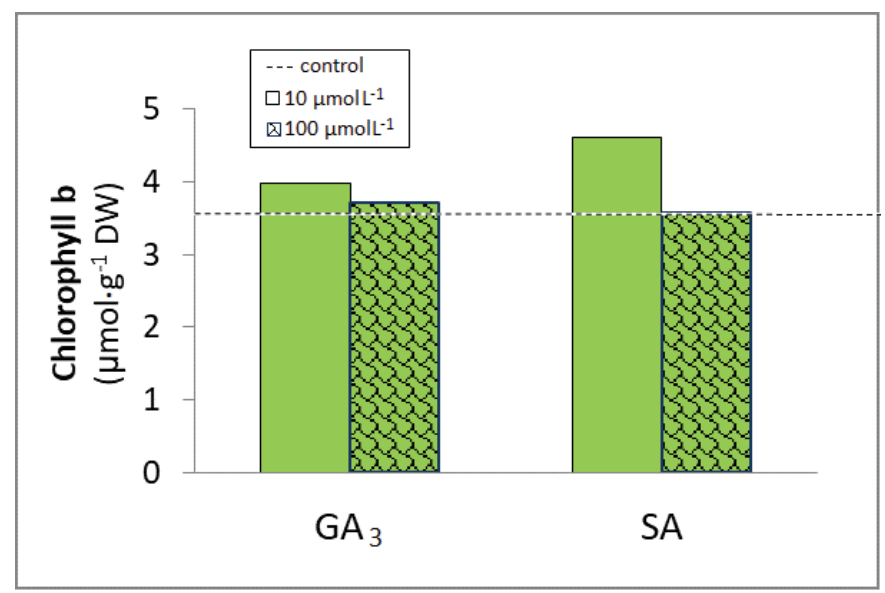

Figure 7. Chlorophyll b concentration in the leaves of wheat plants exposed to $\mathrm{GA}_{3}$ or SA (vertical bars), compared to control (dotted line)

Chlorophyll b (Chl b) concentration in control plants was $3.55 \pm 0.24$ $\mu \mathrm{mol} \cdot \mathrm{g}^{-1} \mathrm{DW}$. In the samples exposed to phytohormones, $\mathrm{Chl} \mathrm{b}$ followed a similar trend of variation as $\mathrm{Chl}$ a, but greater increases were observed at $10 \mu \mathrm{mol} \cdot \mathrm{L}^{-1} \mathrm{GA}_{3}$ and SA, with $15 \%$ and $30 \%$, respectively 
compared to control, (Figure 7). Again, the 10-fold increased exogenous supply of the above mentioned phytohormones restored $\mathrm{Chl} \mathrm{b}$ content to control values.

Total Chl concentration in control plant leaves was of $13.95 \pm 0.97$ $\mu \mathrm{mol} \cdot \mathrm{g}^{-1} \mathrm{DW}$; increased values with $10 \%$ and $25 \%$ were observed in plants grown on media with $10 \mu \mathrm{mol} \cdot \mathrm{L}^{-1} \mathrm{GA}_{3}$ and SA, respectively.

Thus, one can conclude that lower concentrations of the tested hormones promoted chlorophylls biosynthesis in wheat leaves, with SA being more effective than $\mathrm{GA}_{3}$ in this regard.

Carotenoids contents of the wheat plants. The carotenoid pigments usually present in higher plants' leaves are $\beta$-carotene and a few xanthophylls, of which lutein is the most abundant. Leaves of the wheat plants grown on media without added phytohormones had a total carotenoids content (the sum of $\beta$-carotene and xanthophylls concentrations) of $2.70 \pm 0.21 \mu \mathrm{mol} \cdot \mathrm{g}^{-1} \mathrm{DW}$ (Figure 8).

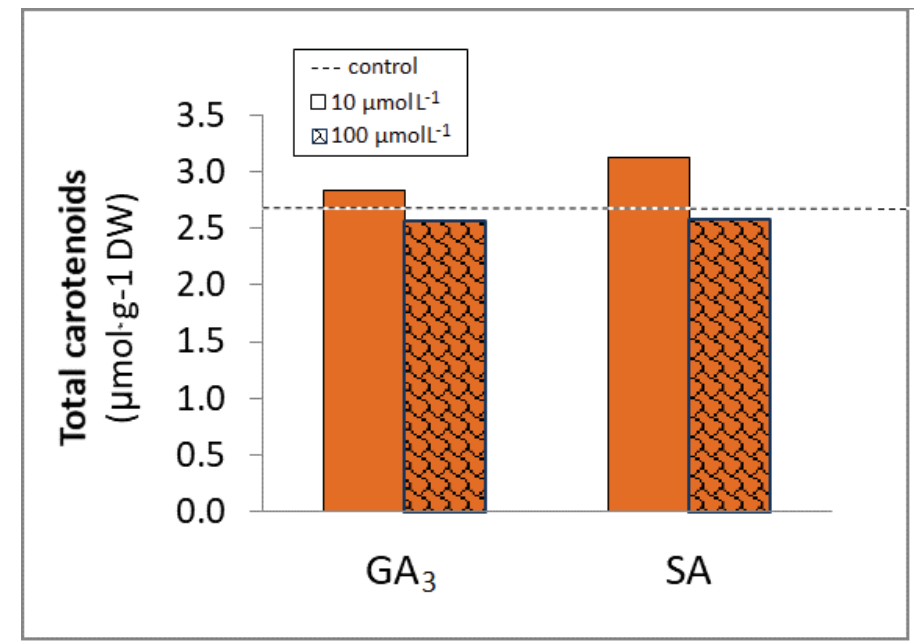

Figure 8. Total carotenoids concentration in the leaves of wheat plants exposed to $\mathrm{GA}_{3}$ or SA (vertical bars), compared to control (dotted line)

The total carotenoid concentration (Car) slightly increased in the plants grown on media containing $10 \mu \mathrm{mol} \cdot \mathrm{L}^{-1} \mathrm{GA}_{3}$ or SA, with about $5 \%$ and $15 \%$ respectively, compared to control. Minor decreases of carotenoids content occurred when wheat plants were exposed to 10 times higher concentration of the tested phytohormones, compared to the unexposed ones. As with the previously presented chlorophylls 
concentrations, low to moderate differences among the experimental variants were observed.

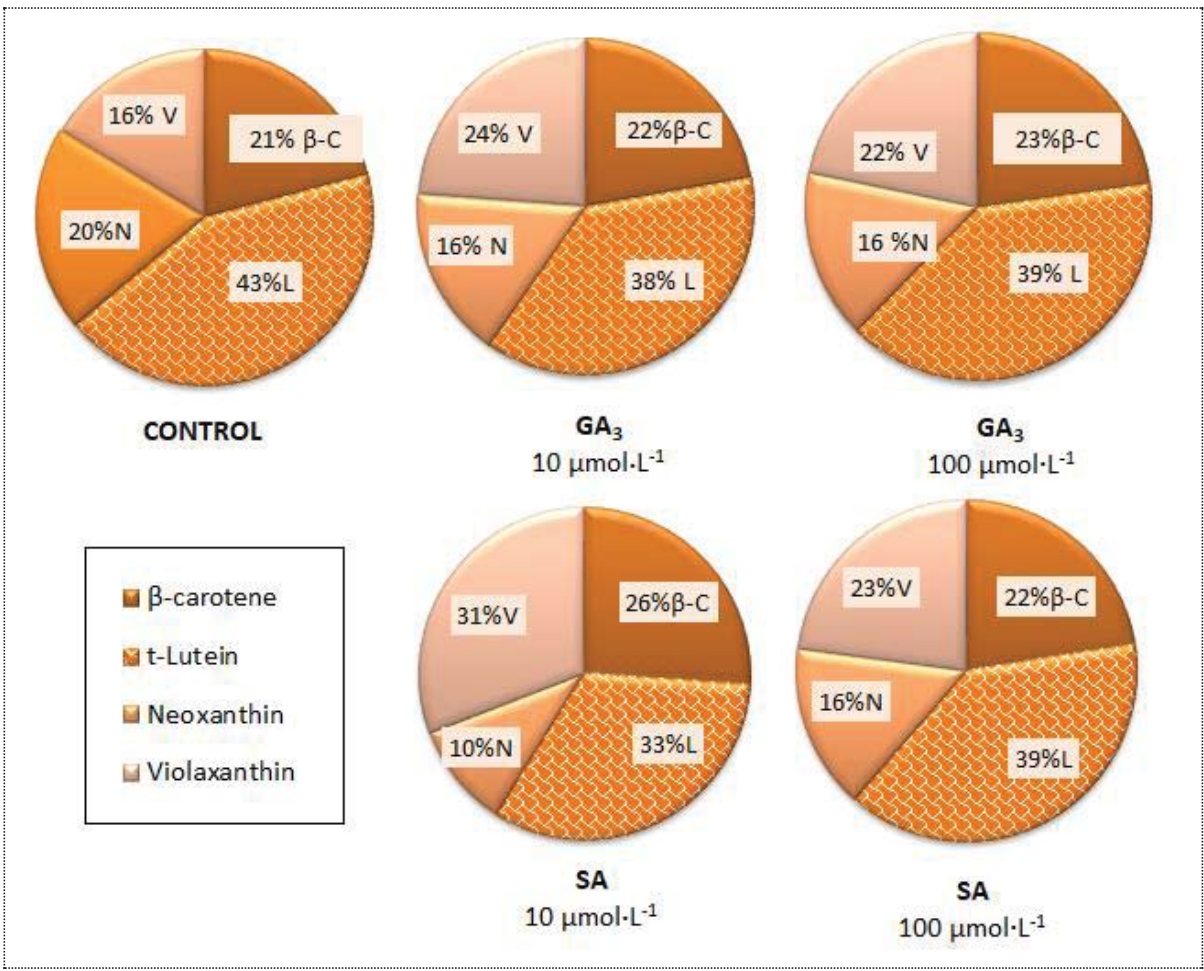

Figure 9. Relative contribution of each pigment in the carotenoid pool, as percent from the total concentration. Abbreviations: $\beta-C-\beta$ carotene, L-lutein, N-neoxanthin, V-violaxnthin

Among the measured carotenoids in wheat plants leaves, lutein was the most abundant, followed by $\beta$-carotene (Figure 9). Significant variations from control were observed regarding the concentrations of two xantophylls: neoxanthin and violaxanthin; while the first decreased, the second increased, and almost doubled compared to control in the plants exposed to $10 \mu \mathrm{mol} \cdot \mathrm{L}^{-1} \mathrm{SA}$. Although the total amount of carotenoids in the leaves of plants exposed to exogenous phytohormones did not differ largely from control (Figure 8), their relative distribution was changed (Figure 9). While $\beta$-carotene concentration appeared to remain almost constant, distinctive variations were observed among the xanthophylls. The diminished conversion of violaxanthin to neoxanthin, increased level of violaxanthin as well as the 
violaxanthin: total carotenoids ratio (Table 1) are indicative for an epoxydative shift of the xanthophyll cycle.

Table 1. Quantitative ratios of the pigments in wheat leaves, as possible indicators of plant adaptation to cultivation conditions. The amounts of pigments in the leaves were expressed as $\mu \mathrm{mol} \cdot \mathrm{g}^{-1} \mathrm{DW}$.

\begin{tabular}{|c|c|c|c|c|c|c|c|}
\hline $\begin{array}{c}\mathrm{GA}_{3} \\
\left(\odot \mathrm{mol} . \mathrm{L}^{-1}\right)\end{array}$ & $\begin{array}{l}\text { Chl a/ } \\
\text { Chl b }\end{array}$ & $\begin{array}{c}\text { Chl }(\mathrm{a}+\mathrm{b}) \\
\text { /Car }\end{array}$ & V/ Car & $\begin{array}{c}\text { SA } \\
\left(\odot \mathrm{mol}^{-L^{-1}}\right)\end{array}$ & $\begin{array}{l}\text { Chl a/ } \\
\text { Chl b }\end{array}$ & $\begin{array}{c}\text { Chl } \\
(\mathrm{a}+\mathrm{b}) / \\
\text { Car }\end{array}$ & $\begin{array}{l}\text { V/ } \\
\text { Car }\end{array}$ \\
\hline 0 & 2.93 & 5.24 & 0.16 & 0 & 2.93 & 5.24 & 0.16 \\
\hline 10 & 2.86 & 5.5 & 0.24 & 10 & 2.8 & 5.67 & 0.31 \\
\hline 100 & 2.85 & 5.64 & 0.22 & 100 & 2.94 & 5.57 & 0.23 \\
\hline
\end{tabular}

\subsection{Data on wheat plants growth}

Growth parameters of the wheat plants cultivated on solidified nutrient solution supplemented either with $\mathrm{GA}_{3}$ or $\mathrm{SA}$ are presented in Figure 10. In control plants, the average values of root length and stem length were $107.67 \pm 3.95 \mathrm{~mm}$ and $148.49 \pm 2.52 \mathrm{~mm}$, respectively (dotted lines).

The presence of gibberellic acid in growth media was followed by minor increases of root and stem length. Compared to control plants, the average length of the roots and stems increased with $1 \%$, and respectively $3 \%$ at $10 \mu \mathrm{mol} \cdot \mathrm{L}^{-1}$ of exogenous GA3. Higher values of the same parameters (with $7 \%$ and $6 \%$ compared to the respective control values) were observed in the plants grown on media supplemented with $100 \mu \mathrm{mol} \cdot \mathrm{L}^{-1} \mathrm{GA}_{3}$. From these data, it can be concluded that exogenous $\mathrm{GA}_{3}$ supply during this experiment did not significantly affect growth of wheat plants, evaluated as the average length of their roots or stems.

At both tested concentrations, average values of stem length of the SA exposed plants were with 3\% lower than control values. Minor stimulation of root growth was observed in SA series (with $8 \%$ and $12 \%$ respectively, at the two tested concentrations).

The differences on plants length between the experimental variants, including control, were not statistically significant (Anova test, $\alpha=0.05$ ). Thus, it can be concluded that exogenous supply of either $\mathrm{GA}_{3}$ 
or SA in the above mentioned conditions (concentration, duration, and route of exposure) had not significantly modified plant growth compared to the unexposed plants.

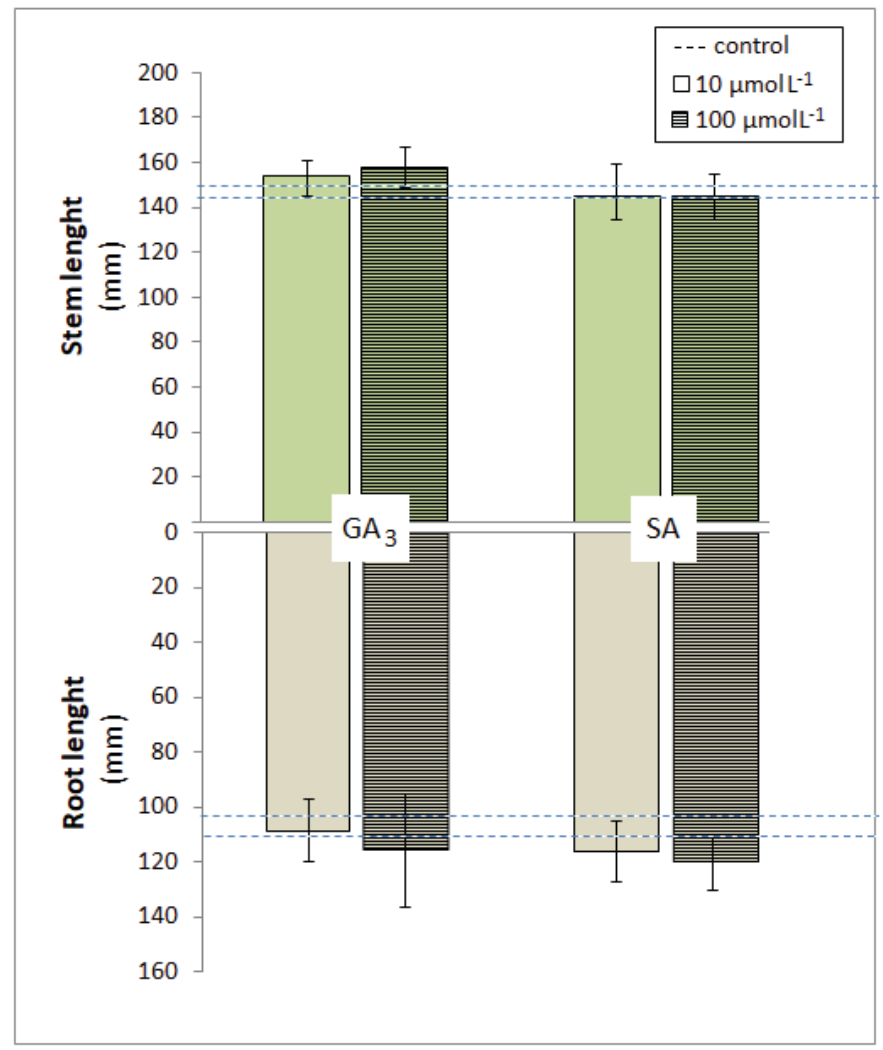

Figure 10. Growth parameters of wheat plants that were exposed to $\mathrm{GA}_{3}$ or SA (vertical bars) compared to the unexposed ones (control)

Similar results were obtained with regard to biomass accumulation; DW:FW ratio didn't vary significantly from one experimental variant to another, the average values being of 0.09 $\mathrm{g}(\mathrm{DW}) \cdot \mathrm{g}^{-1}(\mathrm{FW})$ for the roots, and $0.11 \mathrm{~g}(\mathrm{DW}) \cdot \mathrm{g}^{-1}(\mathrm{FW})$ for the aerial parts (stem and leaves) of the plants.

Growth parameters of the hormone-exposed plants didn't vary compared to control. Biochemical parameters that varied in hormone exposed plants (compared to control) might be considered as part of their adaptive response to an environmental challenge. 


\section{CONCLUSION}

Short-time cultivation of wheat plants on nutrient solutions supplemented with gibberellic acid or salicylic acid did not lead to significant changes in their growth rate, compared to control plants. However, biochemical tests revealed some differences from one experimental variant to another. Increased levels of peroxidase activity, acid phosphatase activity, soluble protein and glucose concentration were detected in the roots of wheat plants exposed to SA, while an increased level of lipid peroxidation products (TBARS) and glucose was observed after the exposure to $\mathrm{GA}_{3}$, compared to control. Although the amounts of photosynthetic pigments did not vary markedly from one experimental variant to another, a distinctive feature of the phytohormones treated plants was the increased proportion of violaxanthin in the carotenoid pool.

The obtained results reflect different adaptive responses of the wheat plants to exogenous GA3 and SA. These could be related to the differences between both the bioavailability in the growth media and the mobility in planta of the two phytohormones, and last but not least, the specific mechanisms of their action.

\section{REFERENCES}

1. B. Zhao, Q. Liu, B. Wang and F. Yuan, J. Agric. Food Chem. 69 (2021) 3566.

2. D. Egamberdieva, S. J. Wirth, A. A. Alqarawi AA, E. F. Abd_Allah and A. Hashem, Front. Microbiol. (2017) 8:2104. doi: 10.3389/fmicb.2017.02104.

3. M. J. Pozo, J. A. Lopez-Raez, C. Azcon-Aguilar and J. M. Garcia-Garrido, New Phytol. 205 (2015) 1431.

4. H. A. S. Alhaithloul, A. M. Abu-Elsaoud and M. H. Soliman, Abiotic Stress Tolerance in Crop Plants: Role of Phytohormones, IntechOpen, 2020 .

5. S. H. Wani, V. Kumar, V. S. Saroj and K. Sah, Crop J., 4 (2016) 162.

6. X. Wang, Q. Li, I. Xie, M. Huang, I. Cai, Q. Zhou, T. Dai and D. Jiang, Crop J., 9 (2021) 120.

7. S. H. Wani, and V. Kumar (Eds), Heat Stress Tolerance in Plants: Physiological, Molecular and Genetic Perspectives, John Wiley \& Sons Ltd., 213-238, 2020.

8. R. Joshi, S. L. Singla-Pareek and A. Pareek, J. Biol. Chem. 293 (2018) 5035.

9. J. X. Zheng, Y. S. Han, J. C. Wang, et al. Medchemcomm. 9 (2017) 181.

10. S. Woo Kim, A. Goossens, C. Libert, F. Van Immerseel, I. Staal and R. Beyaert, Biochem. Pharmacol. 175 (2020) 113866.

11. G. Ciobanu, C. Ionescu, A.A. Boboc, and S. M. Lazar, Annals of the University of Craiova, The Chemistry Series, XLV (2020) 29.

12. H. U. Bergmeyer, Methods of Enzymatic Analysis 1, Academic Press, New York. 2nd Edition, 495, 1974. 
13. A.D. Sharma, N. Shing and J.K. Kang, Gen. Appl. Plant Physiol., 31 (2005) 79.

14. M.M. Bradford, Anal. Chem. 72 (1976) 248.

15. D. M. Hodges, John M. DeLong, C. F. Forney, R. K. Prange, Planta 207 (1999) 604.

16. H. Küpper, S. Seibert and A. Parameswaran, Anal. Chem., 79 (2007) 7611.

17. M. W. Davey, E. Stals, B. Panis, J. Keulemans and R. L. Swennen, Anal. Biochem. 347 (2006) 201.

18. J. D. Alche, Redox Biol., 23 (2019) 101136.

19. M. Morales and S. Munne-Bosch, Plant Physiol. 180 (2019) 1246.

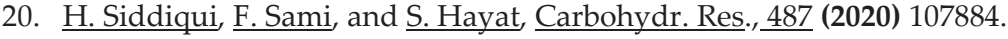

